\title{
Outcomes analysis of Internet-based CME initiatives for diagnosis and treatment of fibromyalgia patients: transition from education to physician behavior to patient health
}

\author{
This article was published in the following Dove Press journal: \\ Neuropsychiatric Disease and Treatment \\ 19 October 2012 \\ Number of times this article has been viewed
}

\author{
Melinda M Somasekhar' \\ Steven Berney ${ }^{2}$ \\ Chris Rausch' \\ James Degnan ${ }^{3}$ \\ 'The Albert J Finestone Office for \\ Continuing Medical Education, \\ ${ }^{2}$ Section of Rheumatology, Temple \\ University School of Medicine, \\ ${ }^{3}$ Measurement and Research Center, \\ Temple University, Philadelphia, \\ PA, USA
}

\begin{abstract}
A well designed outcomes research study was performed in which 20 primary care physicians were selected to participate. Each physician had more than 30 fibromyalgia patients in their practice. The study design consisted of four phases. In phase one, physicians undertook a self-assessment of their practice. Phase two of the study involved diagnosis and treatment of a virtual case vignette. The third phase consisted of analysis of the data from phase two and providing feedback from an expert rheumatologist, and the fourth phase was to complete patient report forms for five patients in their practice. The year-long study was completed by 12 physicians and resulted in data on 60 patients. The results of this study provide an insight into how physicians are diagnosing and treating patients with fibromyalgia. In this study, we transition from continuing medical education to physician behavior to patient outcomes.
\end{abstract}

Keywords: outcomes analysis, Internet, continuing medical education, diagnosis, treatment, fibromyalgia

\section{Introduction}

An assessment of practice-based continuing medical education using patient report forms was described by Finestone in $1986,{ }^{1-3}$ and has become the basis for performance improvement continuing medical education maintenance of certification part IV. ${ }^{4} \mathrm{We}$ report our experience with four different online continuing medical education initiatives concerning diagnosis and treatment of patients with fibromyalgia. To complete each initiative successfully, the physicians had to view the content, take a post-test, and complete an evaluation of the initiative. The four online initiatives used different formats of education. One program was designed as a didactic presentation where experts provided information related to epidemiology, pathophysiology, and the importance of history-taking and complete physical examination including examination of tender points. They also provided insight into diagnosis and treatment of fibromyalgia. In addition, noneducational tools such as downloadable PDFs of all medications approved by the US Food and Drug Administration for treatment of fibromyalgia and pain medications, including opioids and over-the-counter nonsteroidal anti-inflammatory drugs, were provided as a reference point. The second program covered patient-physician interaction (role-playing) showing the importance of taking a history and performing a physical examination in the diagnosis of fibromyalgia. The physician demonstrated the technique for how to check for tender points. The third program involved case-based education, including discussion and debate among
Correspondence: Melinda Somasekhar Temple University School of Medicine Office for Continuing Medical Education, 3440 North Broad Street, Philadelphia, PA 19140, USA

Tel + I 21570747 II

$\mathrm{Fax}+\mathrm{I} 2157078268$

Email somasem@temple.edu 
expert rheumatologists. The fourth program was case-based education with three decision points.

A total of 20,330 health care professionals participated in these four initiatives, and 2468 continuing medical education certificates and 1003 continuing education certificates were issued.

Twenty physicians were selected to participate in the outcomes study. The characteristics of their practices were not known. A self-assessment form, consisting of five questions, was sent to these 20 physicians. We estimated that it would take 5-10 minutes to complete the self-assessment form. All 20 physicians completed the self-assessment form. The second phase of the study involved diagnosis and treatment of a virtual case vignette. Twelve physicians completed the virtual case. The third phase of the study involved analysis of the data provided in phase two of the study and providing feedback to the participants on their performance via a teleconference. Phase four of the study involved chart reviews and completing the patient report forms ${ }^{1-3}$ for five patients. We received data from 60 patients to draw clinically significant conclusions.

\section{Materials and methods}

The objectives of the educational outcomes measurement were to determine changes in knowledge, competence, and performance at the patient level. A well designed outcomes measurement was planned to study the variations and similarities between physicians regarding diagnosis and treatment of patients with fibromyalgia. Two hundred primary care physicians were selected randomly from a pool of 2468 physicians from which 20 physicians were recruited in the outcomes analysis of the online initiatives. The requirement to become a part of the study was that each of these physicians should have more than 30 patients with fibromyalgia in their practice and be willing to make a written commitment to complete the study. Other characteristics of their practices were not known. The data were analyzed to see how many physicians had participated in all four educational initiatives. All 20 physicians had participated in at least two of the online initiatives offered by the office for continuing medical education at Temple University School of Medicine.

In phase one, each physician was required to complete a self-assessment form consisting of five questions as shown in Table 1. In phase two, the participating physicians were asked to diagnose and treat the virtual case shown in Table 2. Phase three of the study involved analysis of the virtual case study data and providing feedback to the participants on their performance via teleconference. In the fourth phase, the participating physicians completed and submitted the
Table I Self-assessment form

I. How much time does it take to diagnose fibromyalgia?

2. Are laboratory tests ordered to rule out autoimmune diseases?

3. Which laboratory tests are ordered, and how do the results help rule out autoimmune diseases?

4. Is a proper history taken, and if so, how does this help in diagnosing fibromyalgia?

5. Are tender points checked?

patient report form shown in Table 3 for five patients with fibromyalgia in their respective practices.

\section{Results}

Completed self-assessment forms were received from all 20 participating physicians. The results of the phase one studies were analyzed. It is interesting to note that

Table 2 The virtual case

Carol is a 47-year-old female. She has been your patient for the last 20 years. Three years ago, she was diagnosed as having rheumatoid arthritis. She is on oral methotrexate, $20 \mathrm{mg}$ weekly and has been feeling well. She sees her rheumatologist at regular intervals for laboratory tests and follow-up care. She visits your office once every 6 months. She presents to your office for a routine visit and complains of anxiety, depression, increased generalized stiffness, pain all over, fatigue, and poor quality sleep. These symptoms have negatively affected her quality of life. You check her joints for inflammation, the soft tissues for tender points (14//8 tender point sites are painful), order laboratory tests, including sedimentation rate and C-reactive protein, and prescribe a selective serotonin reuptake inhibitor, escitalopram (Lexapro ${ }^{\circledR} 10 \mathrm{mg} /$ day). You ask her to take an over-the-counter nonsteroidal anti-inflammatory drug and to see you again in 2-3 weeks Laboratory test results

Erythrocyte sedimentation rate $25 \mathrm{~mm} /$ hour

C-reactive protein $5 \mathrm{mg} / \mathrm{L}$

She visits your office 3 weeks later. Her mood is better. However, she is still somewhat depressed because she is having pain and is unable to sleep. She tells you that her pain medication just did not seem to help. During questioning you find out that her family history is unremarkable. Carol does not smoke tobacco nor drink alcohol. However, she admits she was abused as a child

I. What is her diagnosis?

$\square$ Chronic fatigue syndrome

$\square$ Fibromyalgia

2. What are the next best steps for Carol?

$\square$ Start with nonpharmacologic therapies

$\square$ Heat therapy, particularly at tender points

$\square$ Phototherapy

$\square$ Cognitive behavioral therapy

$\square$ Low carbohydrate diet

$\square$ Discontinue her antidepressant

$\square$ Change to a different antidepressant

$\square$ Amitriptyline $\left(\right.$ Elavi $\left.^{\circledR}\right)$

$\square$ Milnacipran (Savella ${ }^{\circledR}$ )

Pregabalin (Lyrica ${ }^{\circledR}$ )

Duloxetine (Cymbalta $\left.{ }^{\circledR}\right)$ 
Table 3 Patient report form

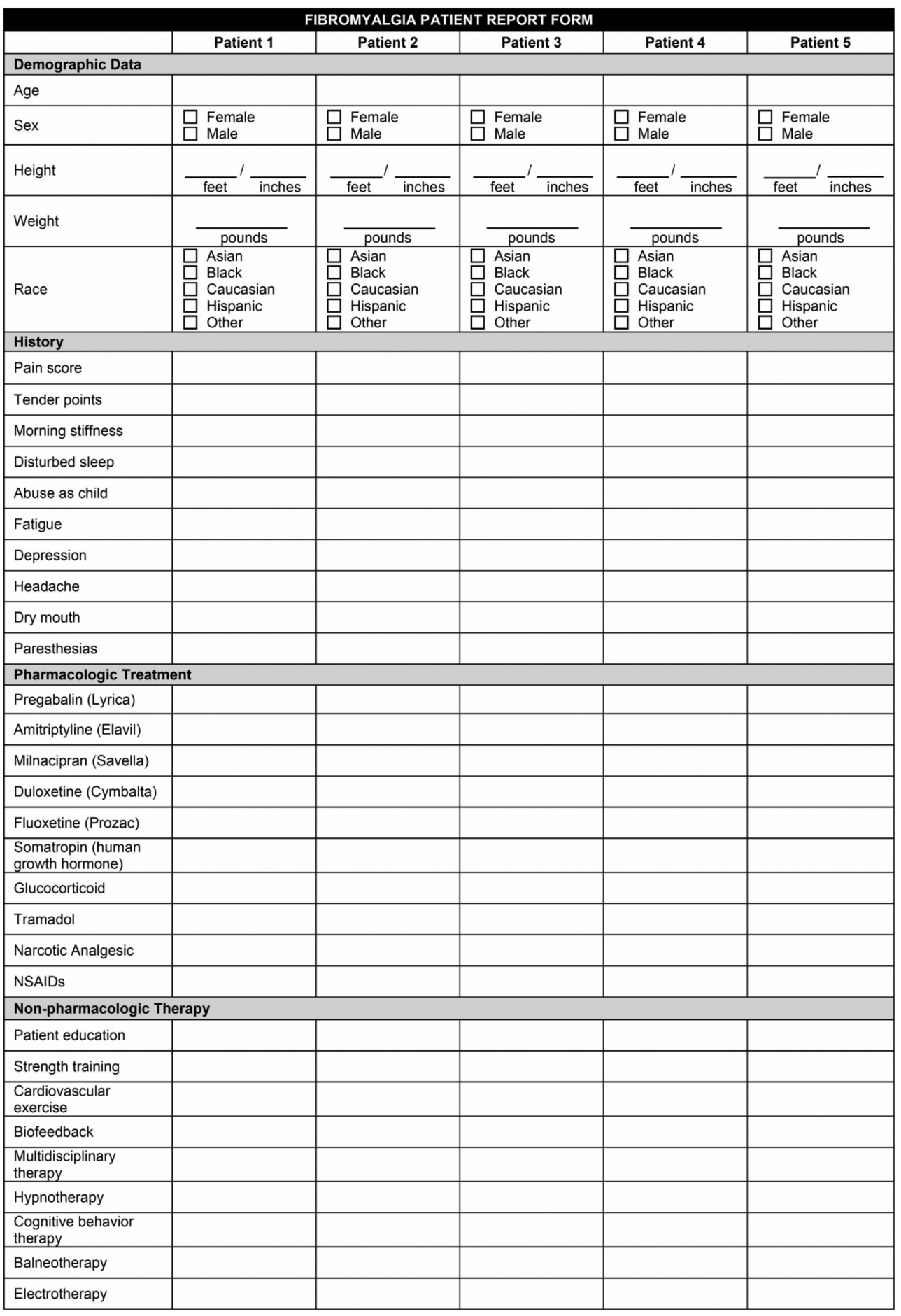

the approach to diagnosis was highly variable. Ten of 20 participants made the diagnosis of the disease during the first visit based on clinical symptoms and results of physical examination. However, these ten physicians ordered other tests, either to ensure that the patient did not have comorbid conditions or to confirm their diagnosis (see Table 4).
The ten participants who did not make the diagnosis of the disease during the first visit used the criteria of exclusions to eventually diagnose fibromyalgia. These ten participants indicated that it took them anywhere from 3 months to 5 years to diagnose fibromyalgia. Although they performed the physical examination and took a detailed history, they still 
Table 4 Response to self-reflection questions reported by physicians

\begin{tabular}{|c|c|c|}
\hline Questions & Responses & Physicians (n) \\
\hline How much time does it take to diagnose & The day of initial physical examination & 10 \\
\hline fibromyalgia? & 90 days to 5 years & 10 \\
\hline Are laboratory tests ordered to rule out & Yes & 17 \\
\hline autoimmune diseases? & No & 3 \\
\hline Which laboratory tests are ordered, & Erythrocyte sedimentation rate & 20 \\
\hline and how do the results help rule out & Rheumatoid factor & 20 \\
\hline \multirow[t]{11}{*}{ autoimmune diseases? } & Antinuclear antibody & 20 \\
\hline & C-reactive protein & 20 \\
\hline & Thyroid-stimulating hormone or thyroid panel & 2 \\
\hline & Hepatitis serology & 2 \\
\hline & Vitamin D & 2 \\
\hline & Infections & 1 \\
\hline & Cancer etiology & 1 \\
\hline & Complete blood count & 3 \\
\hline & Lyme serology & 1 \\
\hline & Lupus erythematosus cell preparation & 3 \\
\hline & Antibodies to double-stranded DNA & 3 \\
\hline Is a proper history taken, and if so, how & History-taking helps the proper diagnosis, pain, stiffness, fatigue, mood & 20 \\
\hline does this help in diagnosing fibromyalgia? & disturbances, lack of inflammation, emotional trauma, childhood abuse, & \\
\hline & anxiety, psychologic component, accident, emotional trauma, lack of sleep, & \\
\hline & effect on life style, quality of life, flash back, nightmares, and diet & \\
\hline Are tender points checked? & Yes & 20 \\
\hline
\end{tabular}

used the process of exclusion to make the diagnosis. They performed all the diagnostic tests to rule out autoimmune disease, such as rheumatoid arthritis and lupus. In addition, they performed a large number of further tests to rule out other diseases (see Table 4).

The consistencies found among the 20 participating physicians were that all 20 took detailed histories from the patients, did physical examinations to check the patients' tender points, and did tests to check for autoimmune diseases, whether to confirm the diagnosis of fibromyalgia they had initially made or to exclude the diagnosis of autoimmune diseases. Although three physicians indicated that they did not order tests to rule out autoimmune disease, they did list a number of tests they ordered which are used to rule out autoimmune disease (see Table 4).

The second phase of the study included the diagnosis and treatment of a virtual patient. Twelve physicians took part in phase two of the study. The data from these studies indicated that 11 participants were able to diagnose the patient as having fibromyalgia. One participant thought the virtual patient had chronic fatigue syndrome. There was a big variation in how participants treated the virtual patient. Four participants were very conservative in their approach and treated the patient only with nonpharmacologic therapies. Two participants changed the patient from Lexapro ${ }^{\circledR}$ (escitalopram oxalate) to Cymbalta ${ }^{\circledR}$ (duloxetine HCI). Four participants were very aggressive in their therapy and treated the patient with Cymbalta and Elavil ${ }^{\circledR}$ (amitriptyline hydrochloride) or Cymbalta and Savella ${ }^{\circledR}$ (milnacipran $\mathrm{HCl}$ ) and other nonpharmacologic therapies, including cognitive behavioral therapy. One physician treated the patient with Cymbalta and cognitive behavioral therapy, and another physician treated the patient with Elavil and other nonpharmacologic therapies (see Table 5).

Phase three of the study involved analysis of the data and providing feedback to the participants on their performance. We were unable to coordinate a teleconference between all the study participants and the expert rheumatologist. Although this step would have helped to educate the participating physicians further, it had no affect on the outcomes

Table 5 Response of physicians to virtual case vignette

\begin{tabular}{|c|c|c|}
\hline Questions & Responses & $\begin{array}{l}\text { Physicians } \\
\text { (n) }\end{array}$ \\
\hline What is the & Chronic fatigue syndrome & 1 \\
\hline diagnosis? & Fibromyalgia & 11 \\
\hline \multirow[t]{9}{*}{$\begin{array}{l}\text { What are the } \\
\text { next best steps? }\end{array}$} & $\begin{array}{l}\text { Start with nonpharmacologic } \\
\text { therapies }\end{array}$ & 9 \\
\hline & Heat therapy at tender points & I \\
\hline & Cognitive behavior therapy & 5 \\
\hline & Low carbohydrate diet & I \\
\hline & Discontinue her antidepressant & I \\
\hline & Change to different antidepressant & 5 \\
\hline & Amitriptyline $\left(\right.$ Elavil $\left.^{\circledast}\right)$ & 3 \\
\hline & Milnacipran $\left(\right.$ Savella $\left.^{\circledR}\right)$ & 2 \\
\hline & Duloxetine $\left(\right.$ Cymbalta $\left.^{\circledR}\right)$ & 7 \\
\hline
\end{tabular}


because all of these physicians had participated in at least two educational initiatives on fibromyalgia sponsored by Temple University School of Medicine.

Twelve physicians participated in phase four of the study in which physicians reported on the symptoms and treatment of five different sets of patients that each physician had treated for fibromyalgia. Of the 60 patients, 56 were female and four were male. All 60 patients were obese. Listed in Table $6 \mathrm{~A}, \mathrm{~B}$, and $\mathrm{C}$ are the numbers of cases in which various symptoms (Table 6A), pharmacologic treatments (Table 6B), and nonpharmacologic treatments (Table 6C) were reported for the 60 patients.

Table 6 Symptoms reported by patients and treatments recommended by physicians

\begin{tabular}{|c|c|c|}
\hline & Cases & $\%$ \\
\hline \multicolumn{3}{|l|}{ (A) } \\
\hline \multicolumn{3}{|l|}{ Symptoms reported } \\
\hline Fatigue & 57 & $95 \%$ \\
\hline Disturbed sleep & 54 & $90 \%$ \\
\hline Morning stiffness & 45 & $75 \%$ \\
\hline Depression & 43 & $72 \%$ \\
\hline Paresthesias & 41 & $68 \%$ \\
\hline Tender points (II or more) & 40 & $67 \%$ \\
\hline Headache & 40 & $67 \%$ \\
\hline Abuse as child & 24 & $40 \%$ \\
\hline Dry mouth & 21 & $35 \%$ \\
\hline Total possible cases & 60 & \\
\hline \multicolumn{3}{|l|}{ (B) } \\
\hline \multicolumn{3}{|l|}{ Pharmacologic treatments } \\
\hline NSAIDs & 35 & $58 \%$ \\
\hline Lyrica $^{\circledR}$ & 34 & $57 \%$ \\
\hline Cymbalta $^{\circledR}$ & 32 & $53 \%$ \\
\hline Narcotic & 27 & $45 \%$ \\
\hline Ultram ${ }^{\circledR}$ & 24 & $40 \%$ \\
\hline Elavil $^{\circledR}$ & 23 & $38 \%$ \\
\hline Savella ${ }^{\circledR}$ & 20 & $33 \%$ \\
\hline Prozac $^{\circledR}$ & 13 & $22 \%$ \\
\hline Glucocorticoid & 9 & $15 \%$ \\
\hline Nutropin ${ }^{\circledR}$ & 2 & $3 \%$ \\
\hline Total possible cases & 60 & \\
\hline \multicolumn{3}{|c|}{ (C) } \\
\hline \multicolumn{3}{|c|}{ Nonpharmacologic treatments } \\
\hline Patient education & 55 & $92 \%$ \\
\hline Cardiovascular exercise & 38 & $63 \%$ \\
\hline Multidisciplinary & 35 & $58 \%$ \\
\hline Cognitive behavior & 26 & $43 \%$ \\
\hline Strength training & 24 & $40 \%$ \\
\hline Electrotherapy & 6 & $10 \%$ \\
\hline Balneotherapy & 5 & $8 \%$ \\
\hline Biofeedback & 4 & $7 \%$ \\
\hline Chiropractice & 2 & $3 \%$ \\
\hline Hypnotherapy & 0 & $0 \%$ \\
\hline Total possible cases & 60 & \\
\hline
\end{tabular}

Abbreviations: CBT, cognitive behavioral therapy; NSAIDs, nonsteroidal antiinflammatory drugs.
Most patients reported fatigue (95\%) and disturbed sleep $(90 \%)$ as the primary symptoms of fibromyalgia. Physicians' primary recommended treatments were patient education (92\%) and cardiovascular exercise (63\%). The most common recommended pharmacologic treatments were NSAIDs (58\%), Lyrica ${ }^{\circledR}(57 \%)$, Cymbalta (53\%), and narcotics (45\%). Given that Ultram ${ }^{\circledR}$ (tramadol) is a narcotic-like pain reliever used to treat moderate to severe pain, it is reasonable to conclude that almost $85 \%$ of the patients were on some kind of narcotic medication (see Table 6B) in addition to medications approved by the Food and Drug Administration for management of fibromyalgia.

Each patient was assessed using a numeric rating scale..$^{5-7}$ The patients were asked to rate their pain intensity by selecting a number on a scale from 0 to 10 (11-point scale). A zero would mean "no pain" and a ten (10) would mean "pain as bad as it could be." The distribution of numeric rating scale pain scores are listed in Table 7A. The average pain score reported by patients was 7.0 with most scores reported in the range of 6-8 (70\%).

In all but one case, patients reported having two or more symptoms. On average, patients reported six different symptoms related to fibromyalgia, with $49 \%$ reporting 7-9 symptoms (see Table 7B).

Physicians recommended, on average, 3.7 pharmacologic treatments and 3.3 nonpharmacologic treatments (see Table 7C and D). Physicians tended to agree on their measurement of patients' reported pain scores. Overall, physicians reported an average patient pain score of 7.1 on a 10-point scale, and no statistical differences were found among the ratings of the 12 physicians $[F(1,11)=0.91, P=0.53]$.

Physicians reported an average of 6.0 symptoms for each patient treated, with the number of reported symptoms ranging from one symptom for one patient to nine reported for four patients. The results of an analysis of covariance showed a significant effect for physicians $[F(1,11)=3.31, P<0.01]$ as well as a significant effect of the covariate (pain scores) $[F(1,11)=12.11, P<0.001]$.

Treatments did not differ significantly between the number of pharmacologic and the number of nonpharmacologic treatments recommended. Physicians recommended, on average, four pharmacologic treatments compared with three nonpharmacologic treatments $[t(1,59)=1.73, P<0.09]$.

Physicians differed with regard to the number of pharmacologic treatments they recommended. Analysis of covariance showed a significant effect for physicians $[F(1,11)=3.02, P<0.01]$, as well as a significant effect of the covariate (pain scores) $[F=12.11, P<0.01]$. 
Table 7 Distribution of pain scores, symptoms reported, and recommended treatments for 60 patients diagnosed with fibromyalgia

\begin{tabular}{|c|c|c|}
\hline Score & Cases & $\%$ \\
\hline \multicolumn{3}{|l|}{ (A) } \\
\hline \multicolumn{3}{|c|}{ Frequencies of reported pain scores } \\
\hline 3 & I & $2 \%$ \\
\hline 4 & 3 & $5 \%$ \\
\hline 5 & 6 & $10 \%$ \\
\hline 6 & 11 & $18 \%$ \\
\hline 7 & 16 & $27 \%$ \\
\hline 8 & 15 & $25 \%$ \\
\hline 9 & 4 & $7 \%$ \\
\hline 10 & 4 & $7 \%$ \\
\hline Total & 60 & \\
\hline Symptoms & Cases & $\%$ \\
\hline \multicolumn{3}{|l|}{ (B) } \\
\hline \multicolumn{3}{|c|}{ Symptoms reported (n) } \\
\hline I & I & $2 \%$ \\
\hline 2 & 2 & $3 \%$ \\
\hline 3 & I & $2 \%$ \\
\hline 4 & 10 & $17 \%$ \\
\hline 5 & 6 & $10 \%$ \\
\hline 6 & 11 & $18 \%$ \\
\hline 7 & 15 & $25 \%$ \\
\hline 8 & 10 & $17 \%$ \\
\hline 9 & 4 & $7 \%$ \\
\hline Total & 60 & \\
\hline Treatments & Cases & $\%$ \\
\hline \multicolumn{3}{|l|}{ (C) } \\
\hline \multicolumn{3}{|c|}{ Pharmacologic treatments recommended (n) } \\
\hline I & I & $2 \%$ \\
\hline 2 & 9 & $15 \%$ \\
\hline 3 & 20 & $33 \%$ \\
\hline 4 & 16 & $27 \%$ \\
\hline 5 & 9 & $15 \%$ \\
\hline 6 & 4 & $7 \%$ \\
\hline 7 & 1 & $2 \%$ \\
\hline Total & 60 & \\
\hline \multicolumn{3}{|l|}{ (D) } \\
\hline \multicolumn{3}{|c|}{ Nonpharmacologic treatments recommended (n) } \\
\hline 0 & I & $2 \%$ \\
\hline I & 4 & $7 \%$ \\
\hline 2 & 15 & $25 \%$ \\
\hline 3 & 15 & $25 \%$ \\
\hline 4 & 12 & $20 \%$ \\
\hline 5 & 11 & $18 \%$ \\
\hline 6 & 1 & $2 \%$ \\
\hline 7 & 1 & $2 \%$ \\
\hline Total & 60 & \\
\hline
\end{tabular}

Similarly, physicians differed with regard to the number of nonpharmacologic treatments they recommended. Analysis of covariance showed a significant effect for physicians $[F(1,11)=2.23, P<0.05]$, without a significant effect of the covariate (pain scores) $[F=0.25, P<0.62]$.

\section{Discussion}

We looked at the clinical behavior of the physicians using a virtual case vignette and patient report form. The results of our study indicate that fibromyalgia is not only difficult to diagnose but is difficult to treat and remains poorly understood by primary care providers because its symptoms can resemble those of many other diseases. According to Blotman et al, $13.1 \%$ of general practitioners made no distinction between fibromyalgia and depression compared with $6.4 \%$ of rheumatologists. ${ }^{8}$ Accurate diagnosis and effective treatment often elude affected patients for years, as shown in Table 4. Diagnosing and managing this disorder is a complex process for both providers and patients, because definitive objective testing does not yet exist and a number of physicians are still using the process of elimination to diagnose patients with fibromyalgia. The results of our study indicate that treatment of fibromyalgia can involve a multimodal mix of nonpharmacologic and pharmacotherapeutic regimens, as seen in Table 6. This can have a negative effect on quality of life for the patient.

The comorbidities associated with fibromyalgia further complicate the diagnosis and management of this condition, so primary care providers must know how to recognize these comorbidities in order to manage patients properly (see Table 6). Primary care clinicians play a critical role in educating and guiding patients through their illnesses. Becoming more familiar with fibromyalgia and its related conditions will help clinicians and their patients develop an integrative approach to symptom management. The results presented in this study indicate that there are some similarities but a lot of variables, as far as diagnosis and treatment of the disease is concerned. Early diagnosis would be helpful to improve the quality of life of the patient and hopefully prevent the comorbidities associated with the disease. According to Buckwalter and Lappin, fibromyalgia typically has an insidious onset and variable course that can make diagnosis difficult. ${ }^{9}$ However, most patients with the disease benefit from early diagnosis and early nonoperative treatments including patient education, patient participation in disease treatment, activity modification, assistive devices, and medications.

Another interesting observation is that, according to criteria published by the American College of Rheumatology (ACR), ${ }^{10}$ the diagnosis of fibromyalgia requires the presence of chronic widespread pain in combination with tenderness on examination at 11 or more of 18 anatomic sites, known as tender points. In this study, 33\% of the patients did not meet the ACR criteria and had fewer than 11 tender points. 
This could add further delay in the diagnosis of the disease. It is quite possible that although primary care physicians know how to check the tender points, they may not have mastery of the practice. Similar observations were reported by Blotman et al. They showed that there are discrepancies in the diagnosis of fibromyalgia made based on tenderness that occurs in precise localized areas of the body (trigger points) by rheumatologists and general practitioners. According to them, rheumatologists were accurate $94 \%$ of the time while general practitioners exhibited an accuracy rate of only $79 \% .{ }^{8}$

The lack of national guidelines makes it difficult for primary care physicians to diagnose and treat patients with fibromyalgia effectively. Hands-on education on how to check tender points for primary care physicians would be of great help. Education tied with maintenance of certification part IV performance improvement continuing medical education for primary care physicians might be helpful in reducing the time until diagnosis and treatment, and hopefully, a greater number of physicians would be willing to participate in the initiative if it was approved by the American Board of Family Physicians and American Board of Internal Medicine.

\section{Conclusion}

There are some similarities but a lot of variations regarding how physicians are diagnosing and treating patients with fibromyalgia. A majority of these patients are on multiple pharmacologic and nonpharmacologic therapies, indicating that the disease has an enormous effect on health-related quality of life.

\section{Acknowledgments}

These four Internet-based educational initiatives were supported by Forest Laboratories, Novartis, and Pfizer. The outcomes research study was not part of the grants. The authors would like to thank Arnold Meyer, Cathy Thomas-King, and Gopalam Somasekhar for providing useful comments.

\section{Disclosure}

The authors report no conflicts of interest in this work.

\section{References}

1. Bowler F, Brading P, Burg F, Finestone AJ, Hubbard J. A practicerelated educational program. JAMA. 1977;237:1346-1349.

2. Finestone AJ, Lanzilotti S, Marks AD, Sobel E. A practice-integrated learning sequence (PILS). Contin Educ Health Prof. 1986;6:2.

3. Finestone AJ, Lanzilotti S, Marks AD, Sobel E. An assessment of practice-based CME. Pa Med. 1987;90:45-46, 48

4. American Medical Association. The physician's recognition award and credit system. Available from: http://www.ama-assn.org/resources/doc/ cme/pra-booklet.pdf. Accessed September 20, 2012.

5. Jensen MP, Karoly P, Braver S. The measurement of clinical pain intensity: a comparison of six methods. Pain. 1986;27:117-126.

6. Bombardier C. Outcome assessments in the evaluation of treatment of spinal disorder: summary and general recommendations. Spine. 2000;25:3100-3202.

7. Haefeli M, Elfering A. Pain assessment. Eur Spine J. 2006; 15 Suppl 1:S17-S24.

8. Blotman F, Thomas E, Myon E, Andre E, Caubere JP, Taïeb C. Awareness and knowledge of fibromyalgia among French rheumatologists and general practitioners. Clin Exp Rheumatol. 2005;23:697-700.

9. Buckwalter JA, Lappin DR. The disproportionate impact of chronic arthralgia and arthritis among women. Clin Orthop Relat Res. 2000;372:159-168.

10. Wolfe F, Smythe HA, Yunus MB, et al. The American College of Rheumatology 1990 criteria for the classification of fibromyalgia. Arthritis Rheum. 1990;33:160-172.
Neuropsychiatric Disease and Treatment

\section{Publish your work in this journal}

Neuropsychiatric Disease and Treatment is an international, peerreviewed journal of clinical therapeutics and pharmacology focusing on concise rapid reporting of clinical or pre-clinical studies on a range of neuropsychiatric and neurological disorders. This journal is indexed on PubMed Central, the 'PsycINFO' database and CAS.

\section{Dovepress}

The manuscript management system is completely online and includes a very quick and fair peer-review system, which is all easy to use. Visit http://www.dovepress.com/testimonials.php to read real quotes from published authors. 